\title{
Design of the Control System of Adaptive Balancing Device Based on PLC
}

\author{
Sha Zhu, Yuexiang Li, Yu Wang, Yonghui Wang \\ School of Petroleum Engineering, Harbin Institute of Petroleum, Harbin, China \\ Email: 563334464@qq.com, lyxalhy1017425@qq.com, wangyude1387@163.com, 37473103@qq.com
}

Received 24 July 2015; accepted 17 August 2015; published 21 August 2015

Copyright (C) 2015 by authors and Scientific Research Publishing Inc.

This work is licensed under the Creative Commons Attribution International License (CC BY). http://creativecommons.org/licenses/by/4.0/

c) (i) Open Access

\begin{abstract}
Due to the well condition and the un-expected imbalance movement of the pumping unit in use, the energy consumes a lot. The existing balancing equipment cannot adjust and monitor the pumping units in real time. Therefore this paper introduces the new adaptive balancing equipmentfan-shaped adaptive balancing intelligent device, projects a design of such control system based on PLC, and determines the principle of the control system, the execution software and the design flow. Site commissioning effect on Daqing Oilfield shows this fan-shaped adaptive balancing intelligent device can effectively adjust and monitor the pumping unit in real time, the balance even adjusts from 0.787 to 0.901 , and integrated energy saving rate is $14.2 \%$. It is approved that this control device is professionally designed, with strong compatibility, and high reliability.
\end{abstract}

\section{Keywords}

Pumping Unit, Fan-Shaped Adaptive Balancing Intelligent Device, Balance Adjustment, Energy Saving, PLC, Remote Control

\section{Introduction}

The existing pumping units are commonly biased compound balanced pumping units, the mechanism of which is adding stationary counterbalance to the tail of pumping unit, thus effectively combining crank-balance and biased compound balanced facility to improve the balance of pumping units. However, problems are that the balance of pumping units cannot be adjusted in real time, and such balance structure also consumes lots of steel, etc. [1]-[3]. To solve these problems, the researchers at home and abroad have been keening on the development of auto-adaptive balancing intelligent units in recent years. And over the years of improvement, researchers have eventually developed new integrated energy saving pumping units and increased integrated balancing technology [4], such as a biased downward barbell type pumping unit, double horse head pumping unit, hydraulic 
pumping unit, and the balanced pumping device [5], etc. Researchers have also added auto-balancing device to the existing pumping unit to realize intelligent control of auto-balancing facility [6] [7]. Ji Xiao-Ke and his partners [8] have developed a mobile balancing intelligent pumping unit controlled by computer cabinet; Wang Xue-Ling et al. [9] put forward a pusher auto-balancing device, both of which above are controlled by RTU system. Deng Si-Ming and his colleagues [10] have designed a balance transfer mobile structure, driven by servo control system. The existing adaptive balancing units are mostly based on overall digitalized control; hence their integrated and complex bodies need more funds.

Aiming at a new auto-adaptive balancing device —-the fan-shaped adaptive balancing intelligent device, this paper presents a program of a design of the control system based on PLC. The control system of the device has strong compatibility and high reliability. Site adjustment effect of the device on Da-Qing Oilfield shows that the device has solved the real time control problems of adaptive balancing pumping unit, achieved the purpose of little investment, strong suitability, energy saving and consumption reduction of the pumping unit, and provided a good design scheme for the research of digitalized pumping units.

\section{The Structure Model of Adaptive Balancing Intelligent Equipment}

Fan-shaped adaptive balancing intelligent device is a balancing component at the rear of the walking beam. It mainly includes: balance boom, sector gear, step-balancing motor, swing arm, swing arm pinion, counterbalance.

The working principle of the device is (as shown in Figure 1): At the rear of the beam, a gear sector is fixed through the balance arm, the both sides of the gear sector connect two swing arms through a fixed axle, one end of the swing arm is fixedly connected to the fixed axle, the other end is connected to the pinion by regulation axes, sector gear and swing-arm pinion sit between two swing-arms, swing-arms engage sector gear and swingarm pinion through the fixed axle and regulation axes separately, and counterbalance is fixed in connection with the pinion and swing arms. When the balance exceeds the set value, the step-balancing motor then drives swing-arm pinion and makes the cunterbalance to move, so that the beam maintains the best balance and finally achieves balance adjustment during the oil pumping. The working principle is shown in Figure 1.

\section{Design of the Control System of Adaptive Balancing Intelligent Device}

\subsection{Control Principle}

Fan-shaped adaptive balancing intelligent device is operated by a strong stability gearing. The main actuator of the control system for adaptive and real-time balance monitoring include: Programmable Logic Controller (PLC), Power-collection Module, Main Motor, Inverter, Angular-displacement Sensor, Load Sensor, Step-balancing Motor, Counterbalance, GPRS Module, command input and display devices. Of the above components, PLC is the main controller, which determines the trackway of the pumping unit over the angular displacement sensor and load sensor, confirms balance condition by calculating balance through current collected in the current collecting module, and simultaneously drives step-balancing motor to adjust the counterbalance in realizing adaptive balance. The main controller connects to a wireless module, which carries out information exchange with remote control system of oil fields. The inverter connects to the main motor and step-balancing motor controls counterbalance. The control logic flow chart is shown in Figure 2.

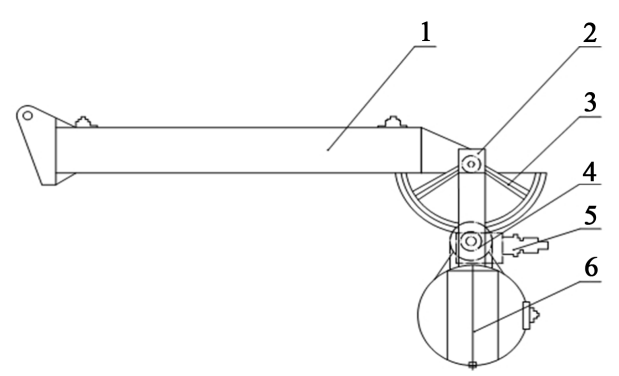

Figure 1. The mechanical system of auto-adaptive balancing intelligent equipment. 1: Balance Boom; 2: Swing Arm; 3: Sector Gear; 4: Swing-arm Pinion; 5: Step-balanceing Motor; 6: Cunterbalance. 


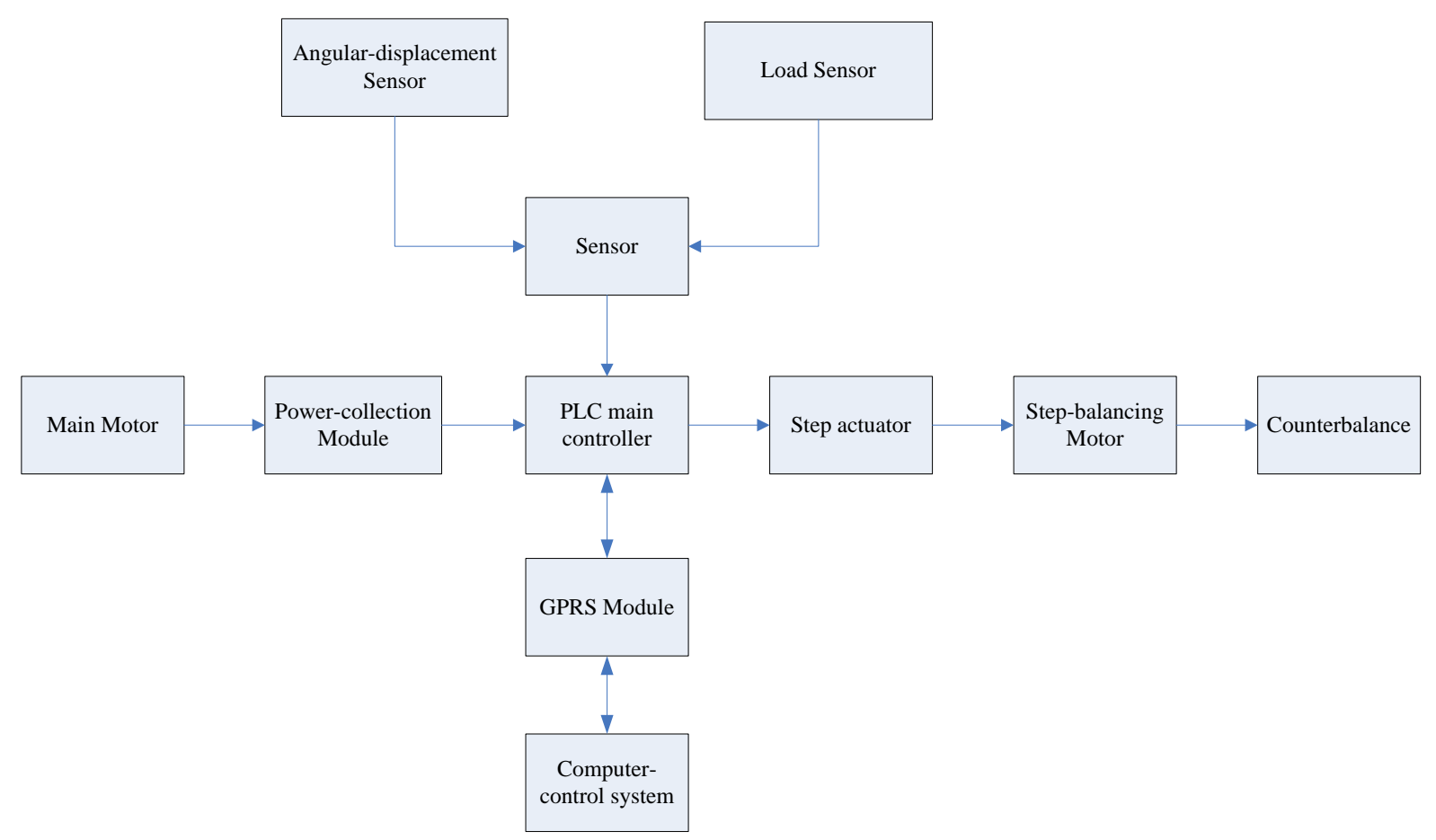

Figure 2. The control logic flow chart of adaptive balancing intelligent device.

\subsection{Hardware Design}

Main controller selects Programmable Logic Controller (PLC), which is in use in industry for 60 years. Even though the operation ability of Omron CP1E Collection CP1E-NA20DR-A is not as good as embedded development board, this brand is sufficient enough to meet the functional requirements of auto-adaptive balancing intelligent equipment. And after half a century of verification, PLC's reliability has been fully recognized by various industries [11].

Angular-displacement sensor chooses Moon Instruments collection SMA36, which measures the rotational position of an object by a linear relationship between current output and axis circumflex angle. Load Sensor uses Moon Instruments collection SMA35GDDC-B, which is designed for polished rod load test of pumping unit on the oil field. All the selected sensors have good performances with a good calmer output, two-wire type regardless positive and negative pole in case of wrongly wiring, and mounting and dismounting conveniently and safely.

Step-balancing Motor picks Billions Stars collection 86BYG250H (including step actuator), which is suitable for mechanical engineering equipment and can operate steadily in low-speed. It can also monitor the pulse signal in real-time with advanced science and technology.

Main-core action devices use Schneider of France and Siemens of Germany, including circuit breaker, contactor, relay and so on. They can enhance the safety and reliability of the control loop and reduce the chance of motor burning accidents.

Except the main power line, in order to avoid field personnel wrongly wiring and burning of devices, all other necessary wiring port and peripheral signal cable interfaces must be in air plug butt docking form. This makes installation much more convenient and efficient.

\subsection{Software Design}

"Balance Beam Pumping Unit Evaluation Criteria" of the fan-shaped adaptive balancing device is determined by the current method, which is deemed equal balance when up-stroke peak torque of the crank shaft of gearbox is as same as that of down-stroke [12]-[14]. Since both the motor input current and power and crankshaft torque of gearbox are approximately in direct proportion, usually the equilibrium ratio (ER) of the main motor peak current in up-down stroke is compared instead of using the peak torque of the crank shaft [15]. When ER of the 
main motor peak current in up-down stroke is equal to 1 , the pumping unit is considered balance. Usually oilfields specify that current ER ranging from 0.8 to 1.1 is considered balance.

VB6.0 is used for compiling the main control system. When the fan-shaped adaptive balancing device is at work, PLC analyzes up-down strokes based on the changing signal of the angular displacement sensor. At the same time, the current acquisition module gathers the maximum up-down stroke current from main motor and calculates the equilibrium ratio (ER) of the main motor peak current in up-down stroke, which equals to the current calculating of the balance of the pumping unit. After comparing with the set value, a command is sent to drive the step-balancing motor to adjust the counterbalance position of the sector gear by using the swing arm, until the actual operating current ratio (the degree of balance) equals to the set value. Fan-shaped adaptive balancing intelligent process is implemented in this way. The wireless module GPRS, which carries out information exchange with remote control system of oil fields, is connected to PLC. The control system flow chart is shown in Figure 3.

\section{Field Experiments}

In February 2015, we carried out an experiment at the well site of the 2 oil brigade Daqing Oilfield, China. The fan-shaped adaptive balancing intelligent device is installed on several 10-type pumping units to conduct balance adjustment. The experimental results are shown in Table 1. It is apparent that the experimental effect with the fan-shaped adaptive balancing intelligent device is better than with original pumping units.

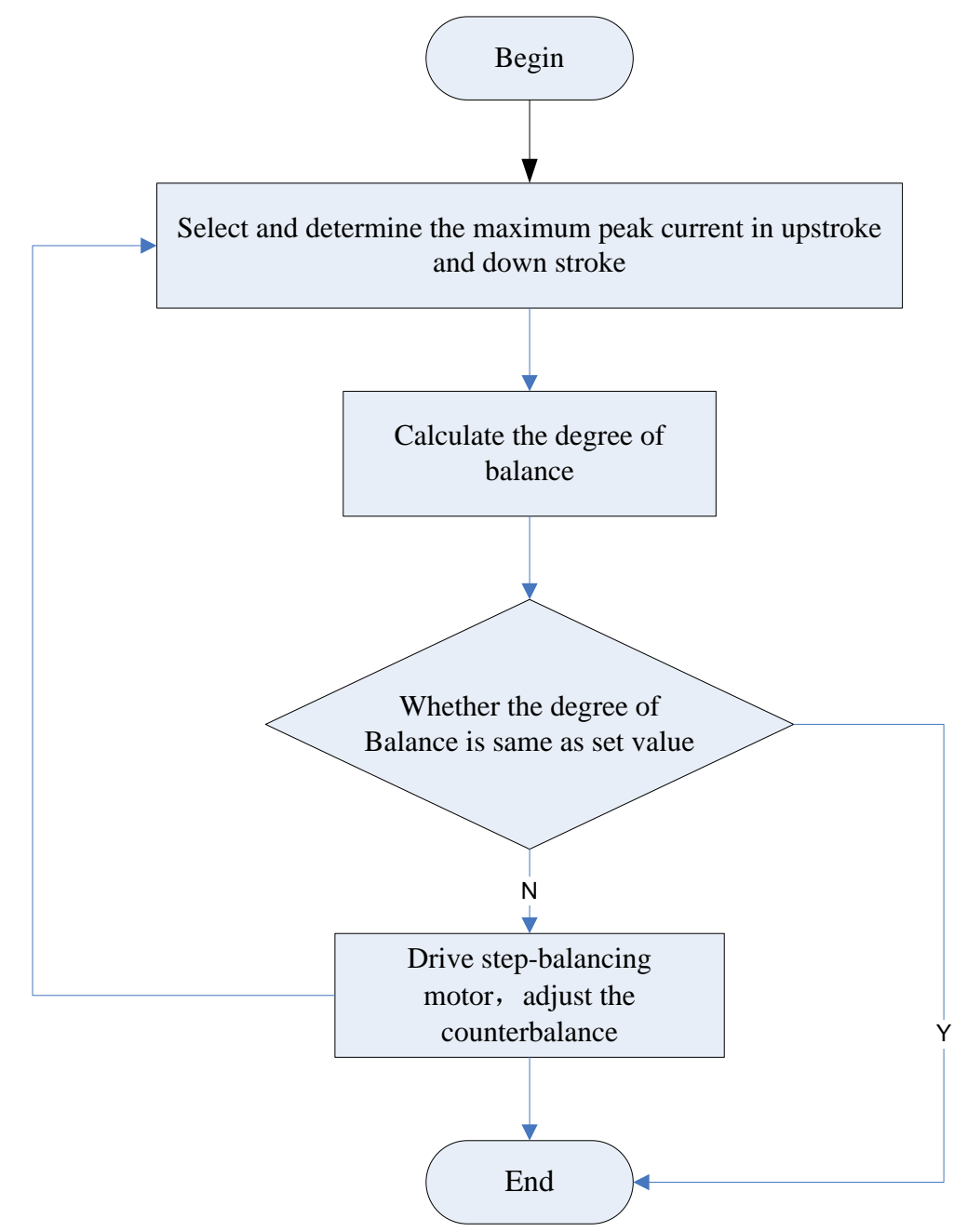

Figure 3. The control system flow chart of the fan-shaped adaptive balancing intelligent device. 
Table 1. The experimental results.

\begin{tabular}{|c|c|c|c|c|}
\hline Pumping stroke (m) & & & Pumping speed (r/min) & 6 \\
\hline \multirow{2}{*}{ Balance mode } & \multicolumn{2}{|c|}{ Peak current (A) } & \multirow{2}{*}{$\begin{array}{l}\text { Degree of } \\
\text { balance }\end{array}$} & \multirow{2}{*}{$\begin{array}{c}\text { Integrated } \\
\text { energy-saving rate }\end{array}$} \\
\hline & Upstroke & Downstroke & & \\
\hline Crank balance & 45 & 35 & 0.787 & \multirow{2}{*}{$14.2 \%$} \\
\hline Self-intelligent balance & 35.79 & 32.24 & 0.901 & \\
\hline
\end{tabular}

After the fan-shaped adaptive balancing intelligent device is installed, degree of balance of pumping unit that is in unbalanced state is adjusted to 0.901 , which drops in the preset range of $0.8-1.1$. Thus the balance of pumping units is improved effectively. In addition, integrated energy-saving rate of the pumping units can reach around $14.2 \%$, better than original pumping units.

Computer control system displays the pumping unit balance, peak current and other operating parameters to achieve manual and automatic balance function adjustment. This device reduces labor intensity, and improves work efficiency.

\section{Conclusion}

This paper proposes solutions based on PLC for the actual control requirement of the fan-shaped adaptive balancing intelligent device for pumping unit, gives the overall design scheme, introduces the implementation details of hardware and software, issues a command to balance motor automatically, achieves automatic adjustment function, maintains the balance of the device in an optimum range, reduces the peak current, and achieves the purpose of energy saving. Site commissioning results show that the system design is reasonable, reliable, and provides references to similar construction machinery control system.

\section{References}

[1] Zhu, X.-M. (2014) A Summary of Energy-Saving Technology of Beam Pumping Unit. Inner Mongolia Petrochemical Industry, No. 17, 117-118.

[2] Peng, H.-T. (2014) Energy-Saving Analysis and Design Calculation of the Down-deviation Compound Balance Beam Pumping Unit. Northeast Petroleum University, Daqing.

[3] Li, X.-Y. (2012) Research on Energy Saving Control of Beam Pumping Units. Northeastern University, Shenyang.

[4] Liang, H.-B., Yi, L.-N. and Meng, Q.-W. (2011) Summary on the Energy-Saving Technical Transformation of Beam Pumping Unit. Applied Energy Technology, No. 2, 4-7

[5] Ma, B.-S. (2015) Application Effect of the New Balance Beam Pumping Unit of Analysis. Chemical Engineering \& Equipment, No. 4, 69-73.

[6] Ji, X.-K. (2013) The Research of Pumping Balance Technology on Domestic and Foreign. Petroleum Geology and Engineering, 27, 121-124.

[7] Liang, Z.-B. (2014) Design of Automatic Balance Beam Pumping Unit. Mechanical Engineers, No. 10, $206-207$.

[8] Ji, X.-K. and Xu, L. (2013) Development and Application of a New Type of Digital Pumping Unit. China Petroleum Machinery, 41, 96-99.

[9] Wang, X.-L. and Xue, Z.-J. (2014) Development and Application of Self-Balancing Intelligent Pumping Unit. China Petroleum Machinery, 42, 82-85.

[10] Deng, S.-Z. and Zhang, D.-X. (2014) Design and Application on Auto-Balancing Device of Walking-Beam Pumping Unit. Journal of Oil and Gas Technology, 36, 231-233.

[11] Shen, F.-Q. and Jiang, J. (2015) Control System Design of Crushing Vehicle mounted Machines Based on PLC. Electric Drive, 45, 74-76.

[12] Wan, B.-L. (1988) Oil Mechanical Design and Calculations. Petroleum Industry Press, Beijing.

[13] Wu, Y.-J., Liu, Z.-J. and Zhao, G.x. (1994) Pumping Unit. Petroleum Industry Press, Beijing.

[14] Qin, W. and Xi, X. (2012) Design of Beam Pumping Unit Balancing Adjustment. Device Advanced Materials Research, 524-527, 1368-1371. http://dx.doi.org/10.4028/www.scientific.net/AMR.524-527.1368

[15] Liang, H.-B. and Wang, J.-X. (2013) Study on Balance Principle of Beam-pumping Unit. Oil Field Equipment, 42, 16-19. 